\title{
Spleen Scan for ${ }^{68} \mathrm{Ga}$-DOTATOC PET-Positive Pancreatic Tail Lesion: Differential Diagnosis of Neuroendocrine Tumor from Accessory Spleen
}

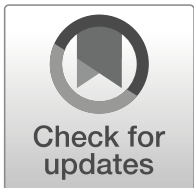

\author{
Hyun Gee Ryoo ${ }^{1} \cdot$ Hongyoon Choi ${ }^{1} \cdot$ Gi Jeong Cheon ${ }^{1}$
}

Received: 29 July 2019 /Revised: 19 November 2019 / Accepted: 25 November 2019 / Published online: 9 December 2019

(C) Korean Society of Nuclear Medicine 2019

\begin{abstract}
${ }^{68} \mathrm{Ga}$-DOTATOC PET/CT is widely used as a functional imaging technique in the detection and characterization of neuroendocrine tumors (NETs). Pancreatic NET and intrapancreatic accessory spleen (IPAS) have similar radiologic characteristics in anatomical imaging and usually show high uptake of ${ }^{68} \mathrm{Ga}$-DOTATOC. Thus, it is challenging to make a differential diagnosis between NET and IPAS when the tumor-like lesion is located in the pancreatic tail. Here, we present a case of ${ }^{68} \mathrm{Ga}$-DOTATOC PET-positive pancreatic tail lesion with high arterial enhancement on CT and MRI. Since ${ }^{99 \mathrm{~m}}$ Tc-labeled damaged red blood cell does not accumulate on NET, a negative spleen scan finding was a crucial diagnostic step to decide surgical resection, which was histologically proven as insulinoma. Our case shows a promising role of additional use of spleen scan with SPECT/CT for the differential diagnosis of ${ }^{68} \mathrm{Ga}$-DOTATOC PET-positive pancreatic NET from the accessory spleen.
\end{abstract}

Keywords ${ }^{68} \mathrm{Ga}$-DOTATOC PET $\cdot$ Spleen scan $\cdot$ Neuroendocrine tumor $\cdot$ Accessory spleen

\section{Introduction}

${ }^{68} \mathrm{Ga}$-DOTA(0)-Phe(1)-Tyr(3)-octreotide $\left({ }^{68} \mathrm{Ga}\right.$-DOTATOC) is a somatostatin analog that binds to the somatostatin receptor (SSTR) expressed on the cell surface. Since the majority of neuroendocrine tumor (NET) mostly expresses SSTR, ${ }^{68} \mathrm{Ga}-$ DOTATOC positron-emission tomography (PET)/computed tomography $(\mathrm{CT})$ is widely used as a functional imaging technique in detection and characterization of NET [1].

In spite of the specificity of ${ }^{68} \mathrm{Ga}$-DOTATOC binding to SSTR, images with high ${ }^{68} \mathrm{Ga}$-DOTATOC uptake should be cautious in the interpretation due to false-positive findings. Accessory spleen occurs in about $10 \%$ of the population, and the second most common location is pancreatic tail [2, 3]. The intrapancreatic accessory spleen (IPAS) is usually characterized by a well-enhanced lesion, similar to the spleen. As NET is a hypervascular tumor characterized by a well-

\section{Hongyoon Choi}

chy1000@snu.ac.kr

1 Department of Nuclear Medicine, Seoul National University Hospital, 101 Daehak-Ro Jongno-Gu, Seoul 03080, Republic of Korea enhanced tumor in CT or MRI, these two lesions have an overlap in anatomical imaging features [4]. Furthermore, splenic tissue exhibits SSTR so that it shows high physiologic uptake on ${ }^{68} \mathrm{Ga}$-DOTATOC PET [5]. Therefore, even though ${ }^{68} \mathrm{Ga}$-DOTATOC is highly specific for SSTR-expressing tumors, it is challenging to make a differential diagnosis between pancreatic NET (pNET) and IPAS because of high uptake on ${ }^{68} \mathrm{Ga}$-DOTATOC PET. Here, we report the case to demonstrate the usefulness of an additional spleen scan for the differential diagnosis of ${ }^{68} \mathrm{Ga}$-DOTATOC PET-positive pNET from the accessory spleen.

\section{Case Report}

A 55-year-old female admitted to our hospital due to a recurrent confusion. The 8 -h fasting glucose level was $57 \mathrm{mg} / \mathrm{dL}$ (normal range $70-110 \mathrm{mg} / \mathrm{dL}$ ), and the Cpeptide was $2.5 \mathrm{ng} / \mathrm{mL}$ (normal range $0.8-4 \mathrm{ng} / \mathrm{mL}$ ) at her initial visit to the hospital. To exclude insulinoma as a cause of the symptoms, a contrast-enhanced abdomen CT scan was performed. At least three hyper-attenuating lesions were detected in the pancreatic uncinate process, pancreatic head, and pancreatic tail. 
${ }^{68} \mathrm{Ga}$-DOTATOC PET/CT was then performed due to the possibility of pNET. ${ }^{68} \mathrm{Ga}$-DOTATOC $(185 \mathrm{MBq})$ was intravenously injected, and PET images from the vertex to the proximal thigh were obtained $60 \mathrm{~min}$ after injection using a dedicated PET/CT scanner (Biograph mCT64, Siemens Healthcare). A low-dose CT scan (120 kVp, $50 \mathrm{mAs}$ ) was acquired for attenuation correction and anatomical localization. CT images were reconstructed into 5-mm-thick slices, and PET images were reconstructed by an iterative algorithm (ordered subset expectation maximization, iteration 2, subset 21). Increased ${ }^{68} \mathrm{Ga}$-DOTATOC uptake was observed in the pancreatic tail lesion, and the maximum standardized uptake value based on body weight was 7.43 (Fig. 1). No additional abnormal increased uptake was observed for the pancreatic uncinate process and pancreatic head lesions. On the contrast-enhanced magnetic resonance imaging (MRI), the pancreatic tail lesion showed isointensity on T1-weighted,
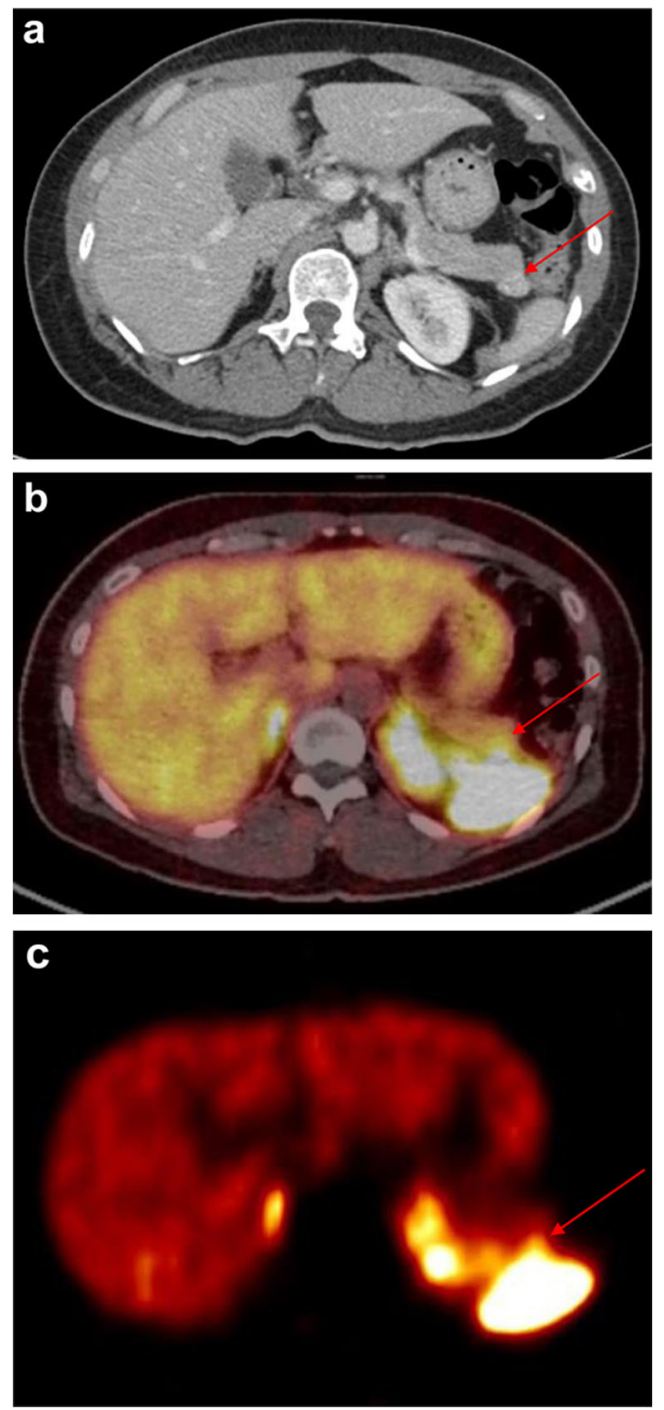

Fig. 1 Contrast-enhanced CT (a) and ${ }^{68} \mathrm{Ga}$-DOTATOC PET/CT (b, c) show an indeterminate lesion in the pancreatic tail with contrast enhancement and focal DOTATOC uptake (arrows) hyperintensity on T2-weighted, hypointensity on diffusionweighted images, and similar contrast enhancement compared with the signal intensity of spleen parenchyma (Fig. 2). Other hyperattenuated lesions in the pancreatic uncinate process and pancreatic head detected on contrast-enhanced CT were not visualized on contrast-enhanced MRI. Besides, these lesions also disappeared on follow-up CT scans. Thus, we speculate that the lesions in the pancreatic uncinate process and pancreatic head were not a true lesion but an artifact.

Since the findings on CT, MRI, and ${ }^{68} \mathrm{Ga}$-DOTATOC PET are both possible in pNET and IPAS, a spleen scan was performed for further diagnostic steps. ${ }^{99 \mathrm{~m}}$ Tc-labeled damaged red blood cell (RBC) (555-740 MBq) was intravenously injected, and spleen scan with SPECT/CT images were obtained $20 \mathrm{~min}$ after injection using a dedicated hybrid SPECT/ CT scanner (Discovery NM/CT 670, GE Healthcare). SPECT images were reconstructed onto $128 \times 128$ matrices using an iterative algorithm (ordered subset expectation maximization, iteration 2, subset 10), and CT images were reconstructed into 3.75-mm-thick slice. No abnormal ${ }^{99 \mathrm{~m}}$ Tc-labeled damaged RBC accumulation was observed including the pancreatic tail (Fig. 3). Because negative finding on spleen scan was not compatible with the accessory spleen, the most possible diagnosis was pNET.

Laboratory work-up revealed normal value of chromogranin A, NSE, CEA, CA 19-9. Plasma glucose (55 mg/dL, normal range 70-110 mg/dL), C-peptide $(3.08 \mathrm{ng} / \mathrm{mL}$, normal range $>3 \mathrm{ng} / \mathrm{mL})$, and insulin $(8.9 \mathrm{uU} /$ $\mathrm{mL}$, normal range $>0.6 \mathrm{uU} / \mathrm{mL}$ ) levels were slightly elevated in 72-h fasting test.

The patient underwent laparoscopic distal pancreatectomy with splenectomy under the impression of pNET. The pancreatic tail lesion was histologically confirmed as grade $1 \mathrm{pNET}$ $(1.9 \times 1.5 \times 1.0 \mathrm{~cm}$ in size, proliferative index Ki-67 2\%) that was positive for insulin (Fig. 4). After the operation, the patient was free from symptoms, and laboratory findings including plasma glucose, C-peptide, and insulin levels became normalized.

\section{Discussion}

Differential diagnosis of NET and accessory spleen is crucial as NET usually needs surgical resection but accessory spleen does not. However, both NET and accessory spleen are positive on ${ }^{68} \mathrm{Ga}$-DOTATOC PET since they exhibit SSTR. As ${ }^{99} \mathrm{~m}$ Tc heat-denatured RBC only accumulates on splenic tissue but not on NET, an additional spleen scan is thus expected to be helpful for the accurate diagnosis of NET with the exclusion of IPAS.

${ }^{68} \mathrm{Ga}$-DOTATOC PET/CT is an accurate diagnostic imaging for NET [6, 7]. Even though its high sensitivity and specificity, physicians should be aware of false-positive or false- 
Fig. 2 MR images of the indeterminate lesion in the pancreatic tail. The pancreatic tail lesion was isointense on T1weighted (a), hyperintense on T2weighted (b), hypointense on diffusion-weighted images $(b$ value $\left.=800 \mathrm{~s} / \mathrm{mm}^{2}\right)(\mathbf{c})$, with similar contrast enhancement on early arterial (d) and delayed (e) phase compared with the signal intensity of spleen parenchyma (arrows)
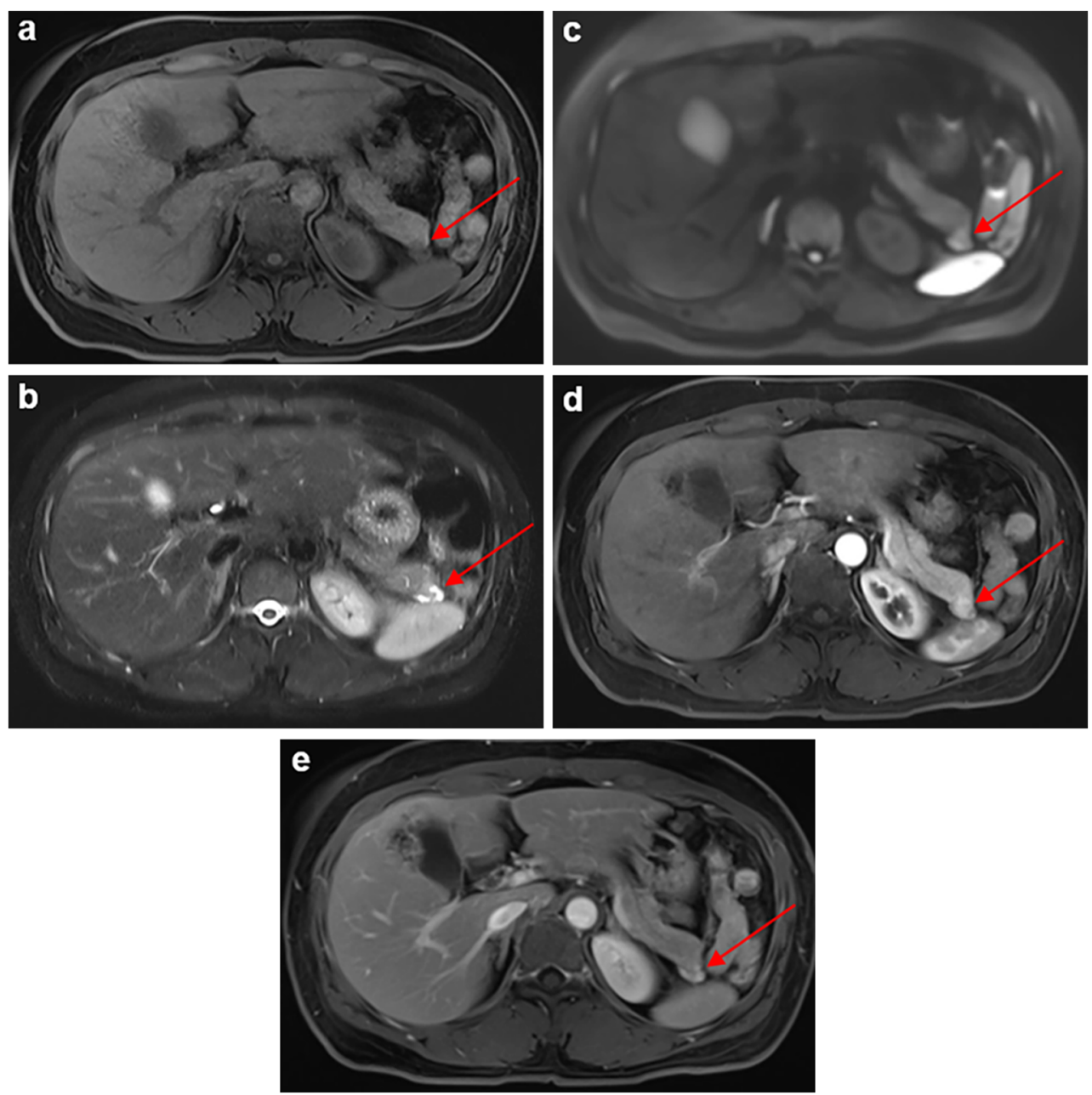

negative PET findings which could lead to an incorrect diagnosis. The uptakes in the pancreatic uncinate process or splenunculi are the most commonly observed physiologic uptake [8]. Osteoblastic osseous process and inflammatory process also demonstrate ${ }^{68} \mathrm{Ga}$-DOTATOC PET uptake since the osteoblasts and white blood cells express SSTR2 [9, 10]. Variable cellular SSTR expression of NET is also related to the ${ }^{68} \mathrm{Ga}$-DOTATOC PET uptake. As poorly differentiated NET has less normal neuroendocrine tissue, the grade of NET has an inverse correlation with ${ }^{68}$ Ga-DOTATOC PET uptake [8]. Compared to other gastrointestinal NET, SSTR imaging shows relatively low sensitivity in detecting insulinoma due to its low content of SSTR2 [11]. For that reason, ${ }^{18} \mathrm{~F}$-DOPA PET, as a tracer of the catecholamine metabolic pathway, is the first-choice proposed diagnostic strategy of functional imaging modality for hyperinsulinism in infants and children for its superiority in diagnosis and localization $[1,12]$. In contrast to benign insulinoma, malignant insulinoma often expresses SSTR2 so that SSTR imaging is recommended [13]. In our case, the pancreatic tail lesion showed increased uptake on ${ }^{68} \mathrm{Ga}$-DOTATOC PET.
Accessory spleens are present in about $10 \%$ of the population. It is most commonly located in the splenic hilum, and the second most common site is the pancreatic tail $(17 \%)[2,3]$. It is usually asymptomatic so that most of the cases are diagnosed incidentally, except for some cases with abdominal pain or idiopathic thrombocytopenic purpura after splenectomy [14]. It is $1-3 \mathrm{~cm}$ in size, well-delimited, homogenous, and hypervascular on CT and MRI $[15,16]$. Tumoral and neuroendocrine markers are usually negative in IPAS, but there has been a report with slightly elevated tumoral markers in the patient with IPAS [17].

Autoradiography and immunohistochemistry studies revealed that the SSTRs were mainly distributed in the red pulp of the spleen [18-20]. SSTR2 was the most abundant subtype expressed in the spleen $(79.7 \%)$ followed by SSTR1 (19.6\%), SSTR4 $(0.6 \%)$, SSTR3 $(0.1 \%)$, and SSTR5 $(0.0 \%)$ [21]. Since accessory spleen exhibit SSTR, it is often challenging to make a differential diagnosis between NET and accessory spleen on ${ }^{68} \mathrm{Ga}$-DOTATOC PET.

IPAS and pancreatic tumor also share similar radiologic characteristics on $\mathrm{CT}$ and MRI $[15,22]$. IPAS and pancreatic 

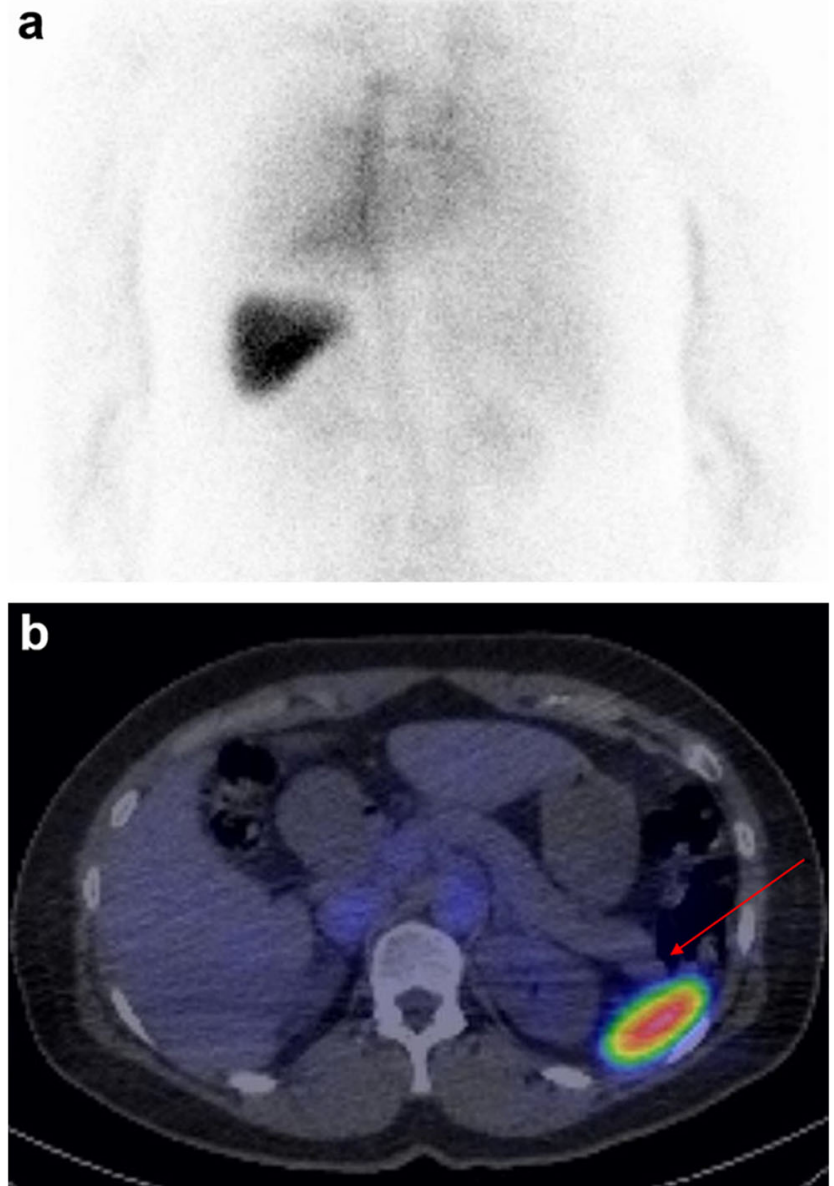

Fig. 3 Spleen scan using ${ }^{99 \mathrm{~m}}$ Tc-labeled damaged RBC with SPECT/CT. Scan image (a) and SPECT/CT fused image (b) demonstrate no abnormal uptake in the pancreatic tail lesion (arrow)

tumor are both hyperattenuating on the arterial phase of enhanced CT. The attenuation of IPAS remains stable on all contrast phases and show persistently high attenuation that matches the density of the spleen. On the contrary, the pancreatic tumor could show iso- or low attenuation on the portal or delayed phase. However, an identical enhancement pattern is sometimes observed for IPAS and pancreatic tumor on

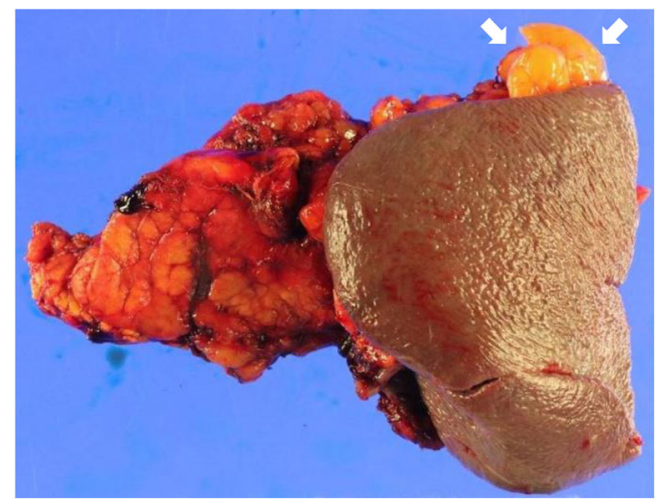

Fig. 4 Gross pathology of insulinoma in the tail of the pancreas with attached spleen (arrows). The tumor was $1.9 \times 1.5 \times 1.0 \mathrm{~cm}$ in size, yellowish nodule with a well-demarcated border
MRI. IPAS usually has T1 low, T2 high signal intensity to pancreas on MRI. IPAS is isointense to normal spleen parenchyma on T1, T2, and diffusion-weighted images. Similar signal intensities with IPAS were observed in $41-50 \%, 18$ $41 \%$, and $68 \%$ of pancreatic tumors on unenhanced T1- and T2-weighted, gadoxetic acid-enhanced dynamic, and hepatobiliary phase MR images, respectively [23]. Overlap of signal intensities between IPAS and the pancreatic tumor is the limitation of MR images for an accurate diagnosis. In our case, pNET had an isointensity on a T1-weighted image with a similar enhancement pattern compared to splenic tissue.

As differentiating IPAS and pNET is a practically important issue in image interpretation, a few previous reports have suggested the usefulness of a spleen scan in the differential diagnosis. Previous studies have shown that positive spleen scan finding revealed accessory spleen for the ${ }^{68} \mathrm{Ga}$ DOTATOC-positive lesions [24-27]. In our case, no uptake in the spleen scan was the crucial step for the differential diagnosis of pNET which was pathologically confirmed after the operation. As future work, a well-designed clinical study may clarify the appropriate indication of ${ }^{68} \mathrm{Ga}$-DOTATOC PET combined with a spleen scan for this purpose. We expect that an additional spleen scan may play an important role in the accurate diagnosis of pNET, which can lead to help us to decide with confidence whether surgical treatment is required.

\section{Compliance with Ethical Standards}

Conflict of Interest Hyun Gee Ryoo, Hongyoon Choi, and Gi Jeong Cheon declare that they have no conflict of interest.

Ethical Approval All procedures performed in studies involving human participants were in accordance with the ethical standards of the institutional and/or national research committee and with the 1964 Helsinki declaration and its later amendments or comparable ethical standards.

Informed Consent The institutional review board of our institute approved this retrospective study, and the requirement to obtain informed consent was waived.

\section{References}

1. Bozkurt MF, Virgolini I, Balogova S, Beheshti M, Rubello D, Decristoforo C, et al. Guideline for PET/CT imaging of neuroendocrine neoplasms with (68)Ga-DOTA-conjugated somatostatin receptor targeting peptides and (18)F-DOPA. Eur J Nucl Med Mol Imaging. 2017;44:1588-601.

2. Dodds WJ, Taylor AJ, Erickson SJ, Stewart ET, Lawson TL. Radiologic imaging of splenic anomalies. AJR Am J Roentgenol. 1990;155:805-10.

3. Halpert B, Gyorkey F. Lesions observed in accessory spleens of 311 patients. Am J Clin Pathol. 1959;32:165-8.

4. Coquia SF, Kawamoto S, Zaheer A, Bleich KB, Blackford AL, Hruban RH, et al. Intrapancreatic accessory spleen: possibilities of computed tomography in differentiation from nonfunctioning 
pancreatic neuroendocrine tumor. J Comput Assist Tomogr. 2014;38:874-8.

5. Sarikaya I, Sarikaya A, Alnafisi N, Alenezi S. Significance of splenic uptake on somatostatin receptor imaging studies. Nucl Med Rev Cent East Eur. 2018;21:66-70.

6. Haug AR, Cindea-Drimus R, Auernhammer CJ, Reincke M, Wangler B, Uebleis C, et al. The role of 68Ga-DOTATATE PET/ CT in suspected neuroendocrine tumors. J Nucl Med. 2012;53: 1686-92.

7. Geijer H, Breimer LH. Somatostatin receptor PET/CT in neuroendocrine tumours: update on systematic review and meta-analysis. Eur J Nucl Med Mol Imaging. 2013;40:1770-80.

8. Hofman MS, Lau WF, Hicks RJ. Somatostatin receptor imaging with 68Ga DOTATATE PET/CT: clinical utility, normal patterns, pearls, and pitfalls in interpretation. Radiographics. 2015;35:50016.

9. Mackie EJ, Trechsel U, Bruns C. Somatostatin receptors are restricted to a subpopulation of osteoblast-like cells during endochondral bone formation. Development. 1990;110:1233-9.

10. Armani C, Catalani E, Balbarini A, Bagnoli P, Cervia D. Expression, pharmacology, and functional role of somatostatin receptor subtypes 1 and 2 in human macrophages. J Leukoc Biol. 2007;81:845-55.

11. Zimmer T, Stolzel U, Bader M, Koppenhagen K, Hamm B, Buhr H, et al. Endoscopic ultrasonography and somatostatin receptor scintigraphy in the preoperative localisation of insulinomas and gastrinomas. Gut. 1996;39:562-8.

12. Blomberg BA, Moghbel MC, Saboury B, Stanley CA, Alavi A. The value of radiologic interventions and (18)F-DOPA PET in diagnosing and localizing focal congenital hyperinsulinism: systematic review and meta-analysis. Mol Imaging Biol. 2013;15:97-105.

13. Wild D, Christ E, Caplin ME, Kurzawinski TR, Forrer F, Brandle $\mathrm{M}$, et al. Glucagon-like peptide-1 versus somatostatin receptor targeting reveals 2 distinct forms of malignant insulinomas. J Nucl Med. 2011;52:1073-8.

14. Bhutiani N, Egger ME, Doughtie CA, Burkardt ES, Scoggins CR, Martin RC 2nd, et al. Intrapancreatic accessory spleen (IPAS): a single-institution experience and review of the literature. Am J Surg. 2017;213:816-20.

15. Spencer LA, Spizarny DL, Williams TR. Imaging features of intrapancreatic accessory spleen. Br J Radiol. 2010;83:668-73.

16. Lancellotti F, Sacco L, Cerasari S, Bellato V, Cicconi S, Ciardi A, et al. Intrapancreatic accessory spleen false positive to $68 \mathrm{Ga}$ Dotatoc: case report and literature review. World J Surg Oncol. 2019;17:117.
17. Lauffer JM, Baer HU, Maurer CA, Wagner M, Zimmermann A, Buchler MW. Intrapancreatic accessory spleen. A rare cause of a pancreatic mass. Int J Pancreatol. 1999;25:65-8.

18. Reubi JC, Waser B, Horisberger U, Krenning E, Lamberts SW, Gebbers JO, et al. In vitro autoradiographic and in vivo scintigraphic localization of somatostatin receptors in human lymphatic tissue. Blood. 1993;82:2143-51.

19. Melis M, Kaemmerer D, de Swart J, Kulkarni HR, Lupp A, Sanger $\mathrm{J}$, et al. Localization of radiolabeled somatostatin analogs in the spleen. Clin Nucl Med. 2016;41:e111-4.

20. Reubi JC, Horisberger U, Kappeler A, Laissue JA. Localization of receptors for vasoactive intestinal peptide, somatostatin, and substance $\mathrm{P}$ in distinct compartments of human lymphoid organs. Blood. 1998;92:191-7.

21. Boy C, Heusner TA, Poeppel TD, Redmann-Bischofs A, Unger N, Jentzen $\mathrm{W}$, et al. 68Ga-DOTATOC PET/CT and somatostatin receptor (sst1-sst5) expression in normal human tissue: correlation of sst2 mRNA and SUVmax. Eur J Nucl Med Mol Imaging. 2011;38: 1224-36.

22. Kim SH, Lee JM, Han JK, Lee JY, Kim KW, Cho KC, et al. Intrapancreatic accessory spleen: findings on MR imaging, CT, US and scintigraphy, and the pathologic analysis. Korean $\mathrm{J}$ Radiol. 2008;9:162-74.

23. Jang KM, Kim SH, Lee SJ, Park MJ, Lee MH, Choi D. Differentiation of an intrapancreatic accessory spleen from a small $(<3-\mathrm{cm})$ solid pancreatic tumor: value of diffusion-weighted MR imaging. Radiology. 2013;266:159-67.

24. Takesh M, Zechmann CM, Kratochwil C, Sahli H, Zein M. Positive somatostatin receptor scintigraphy in accessory spleen mimicking recurrent neuroendocrine tumor. Radiol Case Rep. 2011;6:513.

25. Collarino A, del Ciello A, Perotti G, Rufini V. Intrapancreatic accessory spleen detected by $68 \mathrm{Ga}$ DOTANOC PET/CT and $99 \mathrm{mTc}-$ colloid SPECT/CT scintigraphy. Clin Nucl Med. 2015;40:415-8.

26. Barber TW, Dixon A, Smith M, Yap KS, Kalff V. Ga-68 octreotate PET/CT and Tc-99m heat-denatured red blood cell SPECT/CT imaging of an intrapancreatic accessory spleen. J Med Imaging Radiat Oncol. 2016;60:227-9.

27. Maffey-Steffan J, Uprimny C, Moncayo R, Kroiss AS, Virgolini IJ. Usefulness of combined imaging with (68)Ga-DOTATOC PET/CT and spleen scintigraphy in differentiating a neuroendocrine tumour of the pancreatic tail from splenic lesions in a patient with posttraumatic splenosis. Rev Esp Med Nucl Imagen Mol. 2018;37:325-7.

Publisher's Note Springer Nature remains neutral with regard to jurisdictional claims in published maps and institutional affiliations. 